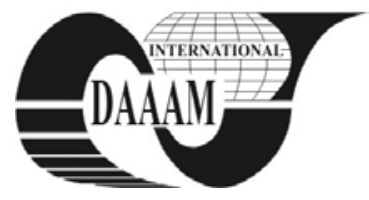

Annals of DAAAM for 2011 \& Proceedings of the 22nd International DAAAM Symposium, Volume 22, No. 1, ISSN 1726-9679 ISBN 978-3-901509-83-4, Editor B. Katalinic, Published by DAAAM International, Vienna, Austria, EU, 2011 Make Harmony between Technology and Nature, and Your Mind will Fly Free as a Bird Annals \& Proceedings of DAAAM International 2011

\title{
A MULTI-AGENT SOLUTION FOR CONTACT CENTERS IMPROVEMENT
}

\author{
POPIRLAN, C[laudiu] I[onut] \& STEFANESCU, C[ostinel] A[ndy]
}

\begin{abstract}
Many companies have been collecting customerrelated data for years and become more complex in their function and organization so that the data searching become more formal to ensure consistency and efficiency. This paper suggests an efficient multi-agent approach for data search in context of contact centers with distributed data bases, considering an adequate case study and presenting experimental results.
\end{abstract}

Key words: software agent, mobile agent, multi-agent system, contact center, data searching

\section{INTRODUCTION}

Agent-based systems (Russell \& Norvig, 2005) claim to be next generation software capable of adapting dynamically to changing business environment and of solving a wide range of knowledge processing application. A multi-agent system is a loosely coupled network of software agents that interact to solve problems that are beyond the individual capacities or knowledge of each problem solver. These multi-agent systems can model complex systems and introduce the possibility of agents having common or conflicting goals. Although sophisticated software agents can be difficult to build from scratch due to the skills and knowledge needed, the widely available agent construction toolkits may provide a quick and easy start to building software agents without much agent expertise. For example, JADE (Java Agent DEvelopment Framework) (Bellifemine et al., 2007) is a software Framework fully implemented in Java language. Significant research and development into multi-agent systems has been conducted in recent years, and there are many architectures available today. The AgentLink project (http://www.agentlink.org, 2005) maintains a list of projects with regard to any kind of agentrelated topics and also maintains a list of available agent toolkits.

A contact center (also referred to as a customer interaction center or e-contact center) is a central point in an enterprise from which all customer contacts are managed. Contact centers are the contemporary successors of call centers. In addition to phone services, they interface with customers via the internet, email, chat and fax.

The design of the modern contact center, and the management of its performance, surely must be based on sound scientific principles. This is manifested by a growing body of academic multi-disciplinary research, devoted to call centers, and ranging from Mathematics and Statistics, to Operations Research, Industrial Engineering, Information Technology and Human Resource Management.

In this paper is presented a multi-agent approach using our preview results (Stoian \& Popirlan, 2010; Popirlan, 2010) for distributed data searching, in context of contact centers. We introduce intelligent software agent model for the searching process of contact center data bases infrastructures. An adequate example in the context of a contact center with search application in distributed data bases show the effectiveness of the Java-based mobile agents approach.

\section{SOFTWARE AGENTS FOR CONTACT CENTER}

\subsection{Developing Mobile Agents using JADE}

In the last few years, several systems and programming environments have appeared to support the development of distributed applications based on intelligent agents (Gams et al., 2009). In JADE agent systems are built using a variety of techniques. For our architecture example [], we use a simple requirements, analysis, design, and development flow, as shown in Figure 1.

A searcher agent is a kind of information agent that has one particular role, which is to find one or more items in a data base. It can be formally implemented as a goal-based or utilitybased agent.

The sub-goals described in Figure 1 will be translated into simple public methods in Java, whereas the overall goal is translated into a JADE Behaviour.

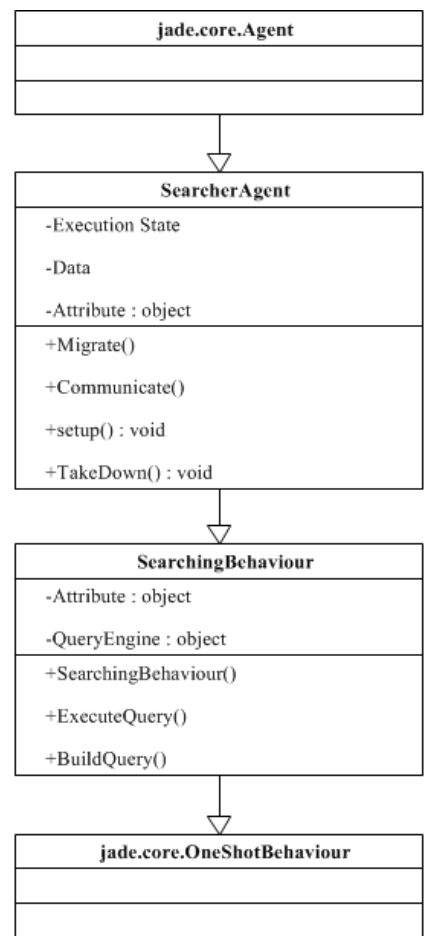

Fig. 1. Object-oriented class diagram for searching process

\subsection{Contact Center - Typical Process}

A contact center would typically be provided with special software that would allow contact information to be routed to appropriate people, contacts to be tracked, and data to be gathered. The contact center architecture is presented in many studies, for example (Popirlan, 2010). A typical process in a contact center can be resumed as follow: The customer dials the call-center number and is greeted with a number of options that include the following: 
- $\quad$ a recorded message followed by the placement in a telephone queue managed by an Automated Call Distribution System (ACD);

- $\quad$ an Integrated Voice Response (IVR) that offers the caller different options where caller interacts with the IVR using a touch-tone telephone or voice control;

- the call is immediately directed by an ACD to an agent who manages the query. If the agent cannot personally resolve the query they direct the call to someone who can answer the query.

In this typical process we will be able to search the data from a distributed data base system. In this respect, the javabased agents visit, one after another, all or a part of the data base servers to whom they ask for certain information.

\section{CASE STUDY AND RESULTS}

In order to illustrate the proposed solution for searching data in contact center with distributed data bases, we will explain the setting and describe a case study. The application exploits mobile agents to reach remote distributed data bases, in contact center context, and locally access data of interest, analyzing them and extracting the required information without any need to transfer the data over the network. For instance, a searcher agent sent to a remote data base can analyze the local data and come back with the attributes that contain a specific keyword. To speed up the research, the application can be shaped after a tree of concurrent searcher agents. If a searcher agent on a local data base finds links to other possibly interesting data on different location (distributed context), it clones itself and has the clones follow these links, to recursively continue the search work on different data bases, as shown in Figure 2.

The main indicator for efficiency, in contact center, is the productivity (Koole, 2007), measured over a certain period (for example, a week).

$$
\text { Productivity }=\mathrm{TWT} /(\mathrm{TVT}+\mathrm{TA}) \times 100 \%
$$

where TWT is total working time and TA is time available. The percentage of calls that is answered in less than a certain fixed waiting time is sometimes called the telephone service factor (TSF). In order to prove the efficiency of solution proposed we will take into account the same scenario that was presented in (Popirlan, 2010) with same values. The "SearcherAgent" creates only one clone ("CloneSearcherAgent") for each of the Data Base Servers (3 clone). The final result which aggregates the clone agent's results was obtained in 0.8 seconds.

\section{CONCLUSION AND FUTURE WORK}

In this paper a multi-agent approach for distributed data searching in context of contact centers was presented. We provide a description of java-based agents, developed in JADE environment, and we presented a simple illustration to show how the proposed system might work.

As a further, we will try to implement agents in order to adopt a control-oriented point of view, for example to request services while they require data/files.

\section{ACKNOWLEDGEMENTS}

The present work was supported by CNCSIS through Grant PCE-II-2008-IDEI-450 no. 954/2009: Knowledge Management for Virtual Organization. Possibilities of Management Assisting using Knowledge Management Systems.

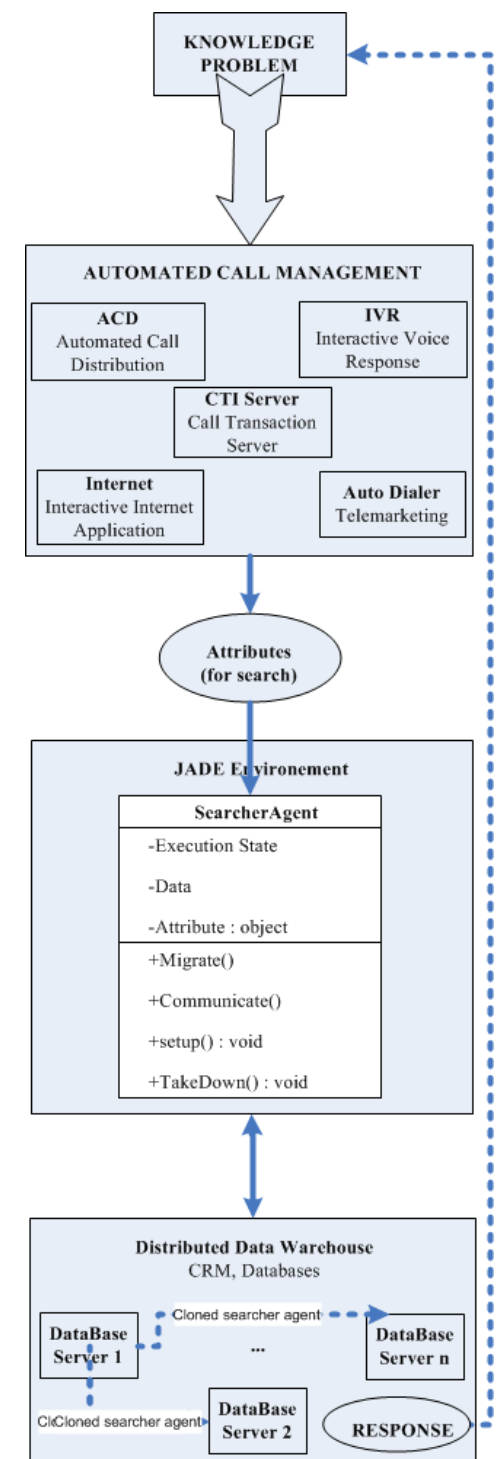

Fig. 2. Using Mobile Agents in Searching Process

\section{REFERENCES}

Bellifemine, F. L.; Caire, G. \& Greenwood, D. (2007). Developing Multi-Agent Systems with JADE, Wiley, USA

Gams, M.; Vlad, M. S.; Mircevska, V.; Cosoi, A. C.; Corduneanu, M. \& Kolbe, M. (2009). Optimising Distributed Access Control Systems using Associative Rules, Annals of DAAAM for 2009 \& Proceedings of the 20th International DAAAM Symposium, 25-28th November 2009, Vienna, Austria, ISSN 1726-9679, ISBN 978-3901509-70-4, Katalinic, B. (Ed.), pp. 1413-1414, Published by DAAAM International Vienna, Vienna

Koole, G. (2007). Call center mathematics, online book http://www.math.vu.nl/ koole/ccmath/

*** (2005) http://www.agentlink.org - The AgentLink project, funded by the European Commission's 6th Framework Program, Accessed on: 2011-01-14

Popirlan, C. I. (2010). Knowledge Processing in Contact Centers using a Multi-Agent Architecture, Wseas Transactions On Computers, Vol. 9, No. 11, 1318-1327, ISSN: 1109-2750, Published Online

Russell, S. \& Norvig P. (2005). Artificial Intelligence: A Modern Approach, Prentice Hall, USA

Stoian, G. \& Popirlan, C. I. (2010). A proposal for an enhanced mobile agent architecture (EMA), Annals of the University of Craiova, Mathematics and Computer Science Series, Vol. 37, No. 1, 71-79, ISSN 1223-6937, Published by Universitaria, Craiova 